\title{
Characterization of Polycrystalline Nickel Cobaltite Nanostructures Prepared by DC Plasma Magnetron Co-Sputtering for Gas Sensing Applications
}

\author{
Oday A. HAMMADI ${ }^{1 *}$ and Noor E. NAJI ${ }^{2}$ \\ ${ }^{1}$ Department of Physics, College of Education, Al-Iraqia University, Baghdad,12001, Iraq \\ ${ }^{2}$ School of Applied Sciences, University of Technology, Baghdad, 35010, Iraq \\ ${ }^{*}$ Corresponding author: Oday A. HAMMADI_ Email: oday.hamadi@yahoo.com
}

\begin{abstract}
In this work, a gas sensor is fabricated from polycrystalline nickel cobaltite nano films deposited on transparent substrates by closed-field unbalanced dual-magnetrons (CFUBDM) co-sputtering technique. Two targets of nickel and cobalt are mounted on the cathode of discharge system and co-sputtered by direct current (DC) argon discharge plasma in presence of oxygen as a reactive gas. The total gas pressure is 0.5 mbar and the mixing ratio of $\mathrm{Ar}: \mathrm{O}_{2}$ gases is $5: 1$. The characterization measurements performed on the prepared films show that their transmittance increases with the incident wavelength, the polycrystalline structure includes 5 crystallographic planes, the average particle size is about $35 \mathrm{~nm}$, the electrical conductivity is linearly increasing with increasing temperature, and the activation energy is about $0.41 \mathrm{eV}$. These films show high sensitivity to ethanol vapor.
\end{abstract}

Keywords: Nickel cobaltite; magnetron sputtering; reactive sputtering; gas sensing

Citation: Oday A. HAMMADI and Noor E. NAJI, "Characterization of Polycrystalline Nickel Cobaltite Nanostructures Prepared by DC Plasma Magnetron Co-Sputtering for Gas Sensing Applications,” Photonic Sensors, 2018, 8(1): 43-47.

\section{Introduction}

Amongst too many metal oxides with spinel structures, nickel cobaltite $\left(\mathrm{NiCo}_{2} \mathrm{O}_{4}\right)$ has been widely used in electrochemistry and sensing devices [1-4]. It is utilized efficiently as electrode material in sodium-ion cells as well as electro-catalyst in alkaline water electrolyzer because of the low-cost production, environmental friendliness, high electrical conductivity, and optical properties in the infrared region of electromagnetic spectrum [5-8]. One reasonably important application such as energy storage is based on the employment of nickel cobaltite as super-capacitors, also known as "electrochemical capacitors" [9]. These devices are characterized by their ultra-high power density, long cycling stability, wide operation temperature range, and improved safety [10-14].

Due to high flexibility, reliability, and low cost of magnetron sputtering technique, atoms from one or more different targets can be sputtered, oxidized, and deposited as nanostructured thin films on different substrates $[15,16]$. These nanostructures can be produced with high purity and homogeneity since the operation parameters and preparation conditions can be precisely controlled [17].

In this work, nickel cobaltite thin films are deposited on transparent substrates by a closed-field

Received: 11 August 2017 / Revised: 10 October 2017

(C) The Author(s) 2017. This article is published with open access at Springerlink.com DOI: $10.1007 / \mathrm{s} 13320-017-0460-y$

Article type: Regular 
unbalanced dual-magnetrons plasma co-sputtering technique. Two targets of nickel and cobalt are co-sputtered in the presence of oxygen as a reactive gas. The optical, structural, and gas sensing characteristics of the deposited films are investigated.

\section{Experiments}

Closed-field unbalanced dual-magnetrons (CFUBDM) plasma co-sputtering system was used to prepare the nickel cobaltite thin films. The magnetron was assembled by two concentric ring permanent magnets. The inner diameter, outer diameter and height of the outer magnet were $40 \mathrm{~mm}$, $80 \mathrm{~mm}$, and $15 \mathrm{~mm}$, respectively, while for the inner magnet, they were $17 \mathrm{~mm}, 32 \mathrm{~mm}$, and $12 \mathrm{~mm}$, respectively. The maximum intensities of magnetic field were measured to be 250 and 180 gauss for the inner and outer magnets, respectively. The distance between the electrodes was $3.5 \mathrm{~cm}$. More details can be found in published works [18-23].

The chamber was first evacuated to $0.01 \mathrm{mbar}$ in order to remove any reactive contaminants or residual particles. Plasma was produced by discharge of argon as a process gas in presence of oxygen as a reactive gas with an $\mathrm{Ar}: \mathrm{O}_{2}$ mixing ratio of 5:1 at total pressure of $0.5 \mathrm{mbar}$, flow rate of $100 \mathrm{sccm}$, discharge current of $40 \mathrm{~mA}$, and discharge voltage of $1.5 \mathrm{kV}$. Both electrodes were cooled to $20{ }^{\circ} \mathrm{C}$ in order to avoid the effects of rising temperatures on the quality of the prepared structures. Pure nickel (99.9\%) and cobalt (96\%) hemispherical sheets of $8-\mathrm{cm}$ diameter were mounted by Teflon mount on the cathode as the targets to be sputtered while the glass substrates were placed on the anode electrode. These substrates were cleaned by ethanol to remove any residuals on their surfaces and then rinsed in distilled water to remove the ethanol before dried by hot air and kept in closed vessel. As the substrate was placed upon the anode, its temperature was expected to be the same as the temperature of the anode $\left(20^{\circ} \mathrm{C}\right)$.

The prepared samples were tested by the ultraviolet, visible, and near-infrared (UV-Visible-NIR) spectrometry in the spectral range $166 \mathrm{~nm}$ - 962 nm using Spectra Academy C110905 spectrophotometer with resolution of $0.2 \mathrm{~nm}$. Also, the X-ray diffract00000ion using $\mathrm{Cu}-\mathrm{Ka}$ Phillips-PW1710 X-ray tube $(\lambda=1.54 \AA)$. The scanning electron microscopy (TESCAN VEGA) was used to determine the particle size of the prepared nanostructures.

Four-point probe (F.P.P.) apparatus was used for the measurements of magnetization with magnetic field. A Keithley 616 picoammeter was used for the measurements of the electrical conductivity, which was equipped with a K-type thermocouple to measure the temperature of the sample. The gas sensitivity of the prepared samples was measured in a glass enclosure with adjustable gas concentration. The value of sensitivity ( $S$ ) was determined by $S=\left|R_{g}-R_{a}\right| / R_{a}$, where $R_{g}$ and $R_{a}$ are the electrical resistances of the thin film in the gas to be sensed and in the air, respectively.

\section{Results and discussions}

The prepared films are visibly grayish-brown in color and Fig. 1 shows the average transmittance and absorbance of $\mathrm{NiCo}_{2} \mathrm{O}_{4}$ films with thickness of $100 \mathrm{~nm}$. It is clear that these films have low transmittance (high absorbance) in the UV region of electromagnetic spectrum. This transmittance is increasing with increasing incident wavelength to reach about $70 \%$ at $900 \mathrm{~nm}$ (NIR).

To introduce the crystalline structure of the prepared samples, the X-ray diffraction (XRD) pattern is recorded, as shown in Fig. 2. Five distinct peaks are identified according to the JCPDS $20-0781$ at $2 \theta$ of 31.7 degree, 36.8 degree, 38.6 degree, 65 degree, and 69.2 degree. These angles correspond to crystallographic planes of (220), (311), (222), (511), and (440), respectively. The polycrystalline structure assigns high purity of the prepared samples as no peaks belonging to pure $\mathrm{Ni}$ or Co are observed on the XRD pattern. Using Scherrer's equation, the average grain size (G.S.) is 
determined to be $2.33 \mathrm{~nm}$. However, the $\mathrm{NiCo}_{2} \mathrm{O}_{4}$ particle size is determined from the scanning electron microscope (SEM) image, shown in Fig.3, to be about $35 \mathrm{~nm}$, which is approximately the average value for all tested samples.

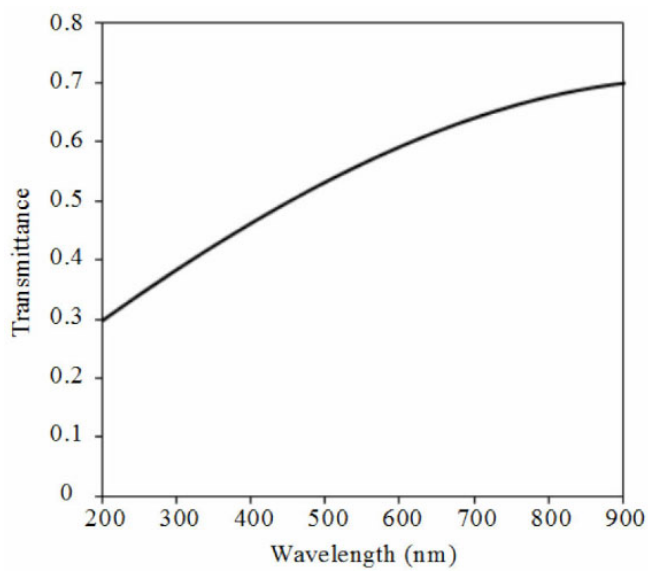

(a)

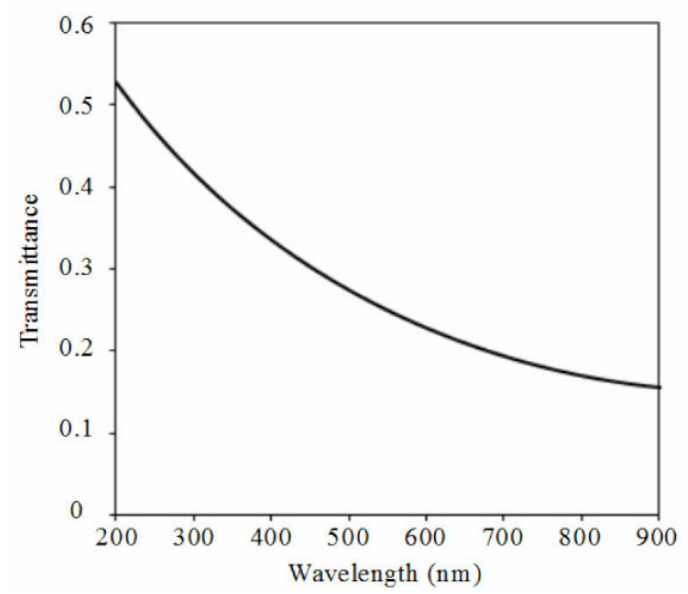

(b)

Fig. 1 Average transmittance (a) and absorbance (b) of $100 \mathrm{~nm} \mathrm{NiCo} \mathrm{O}_{4}$ films in the range of wavelengths $200 \mathrm{~nm}-$ $900 \mathrm{~nm}$.

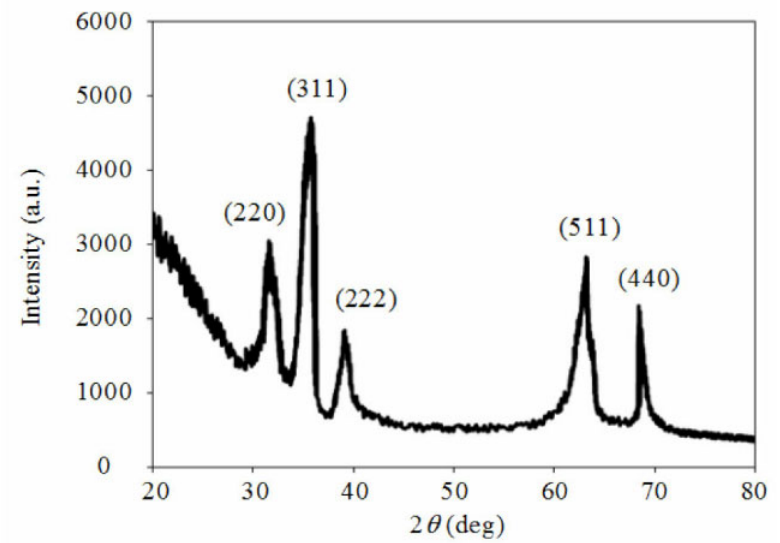

Fig. 2 XRD pattern of the prepared sample of $100-\mathrm{nm}$ thickness.
The electrical conductivity $(\sigma)$ of the prepared $\mathrm{NiCo}_{2} \mathrm{O}_{4}$ films is found to increase with increasing temperature, and this behavior is expected due to the changes in oxygen binding energy. As well, the role of nickel ions in the electrical conduction of this compound is of reasonable importance. In order to determine the thermal activation energy $\left(E_{a}\right)$ of this compound $\left(\mathrm{NiCO}_{2} \mathrm{O}_{4}\right)$, the variation of $\operatorname{Ln}(\sigma)$ with $1000 / \mathrm{T}$ in case of heating $100 \mathrm{~nm}$ film sample is plotted, as shown in Fig. 4. From the slope of produced line, the thermal activation energy is determined to be $0.41 \mathrm{eV}$, which is a little higher than that of degenerate semiconductors.

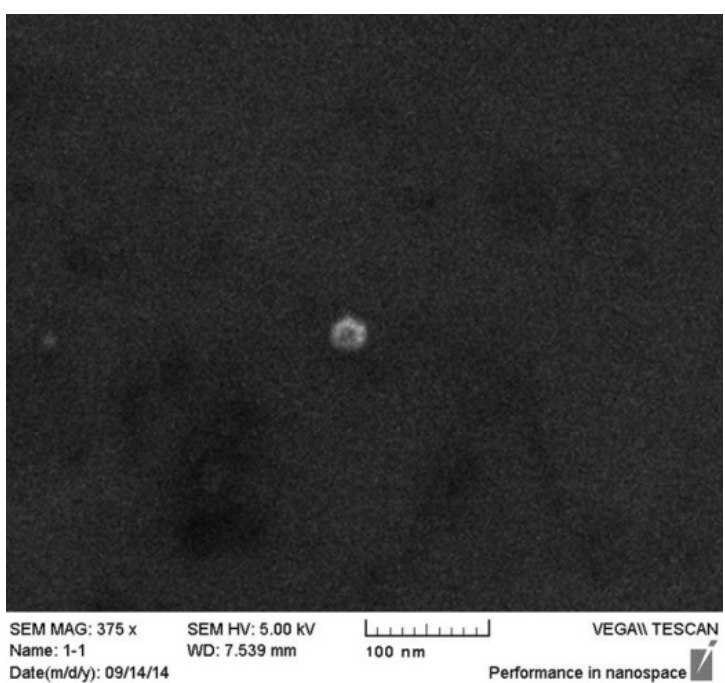

Fig. 3 SEM image of the prepared sample. The particle size is about $35 \mathrm{~nm}$

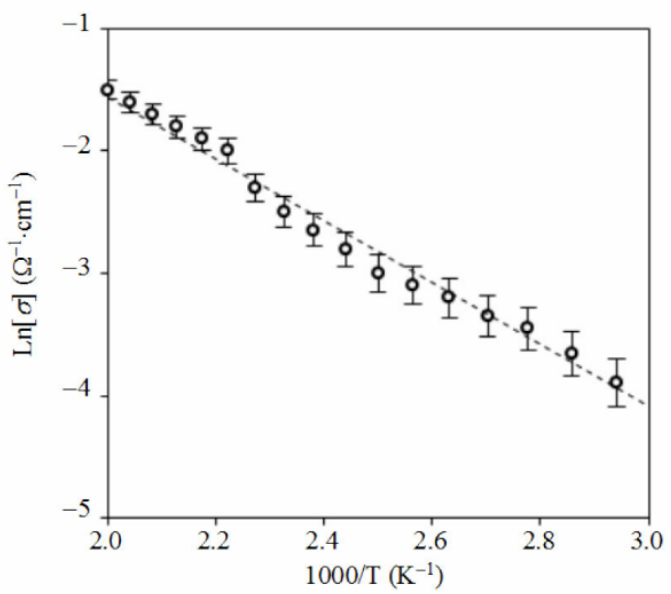

Fig. 4 Plot of $\operatorname{Ln}(\sigma)$ against $1000 / \mathrm{T}$ for $\mathrm{NiCo}_{2} \mathrm{O}_{4}$ thin film during sample heating (thickness is $100 \mathrm{~nm}$ ). The activation energy $\left(E_{a}\right)$ is determined from the slope to be about $0.41 \mathrm{eV}$. 
One of the most promising applications of $\mathrm{NiCo}_{2} \mathrm{O}_{4}$ thin films is their ability to detect gases and vapors. Therefore, the sensitivity of the prepared films to ethanol vapor is measured at room temperature $(300 \mathrm{~K})$, as shown in Fig. 5 , and the maximum value is observed at the sensitivity of 7.5 and the ethanol concentration of $1000 \mathrm{ppm}$. This value of sensitivity can be considered high.

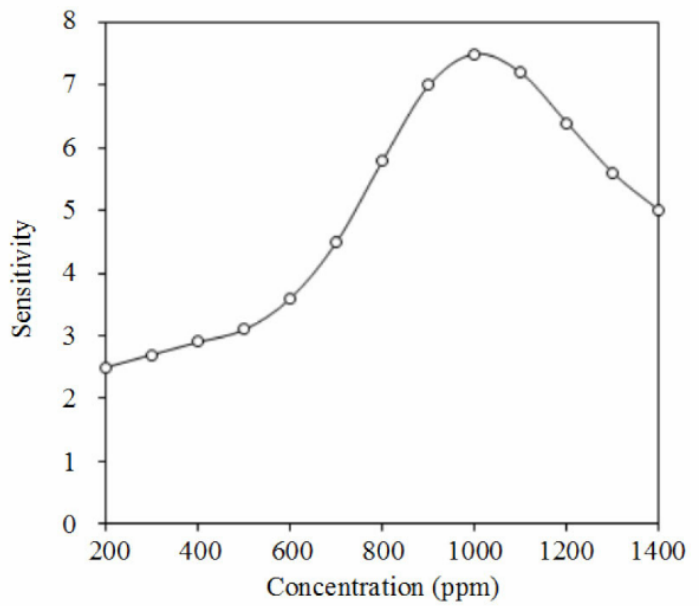

Fig. 5 Measured sensitivity of $\mathrm{NiCo}_{2} \mathrm{O}_{4}$ thin films to the ethanol.

\section{Conclusions}

In concluding remarks, homogeneous and nanostructured nickel cobaltite thin films were prepared and deposited on transparent substrates by magnetron co-sputtering technique. Thin films of $100-\mathrm{nm}$ thickness were partially transparent. These films were polycrystalline with high structural purity, and a minimum particle size of $25 \mathrm{~nm}$ was observed. Thermal activation energy of the prepared sample was $0.41 \mathrm{eV}$. High sensitivity of the prepared films to ethanol was measured at room temperature. The magnetron co-sputtering technique is a low-cost, flexible and reliable technique to prepare $\mathrm{NiCo}_{2} \mathrm{O}_{4}$ nanostructures.

\section{Acknowledgment}

Authors would like to thank people at Plasma-Processing Lab at University of Central Oklahoma (USA) for the experimental assistance during the work.
Open Access This article is distributed under the terms of the Creative Commons Attribution 4.0 International License (http://creativecommons.org/ licenses/by/4.0/), which permits unrestricted use, distribution, and reproduction in any medium, provided you give appropriate credit to the original author(s) and the source, provide a link to the Creative Commons license, and indicate if changes were made.

\section{References}

[1] J. G. Kim, D. L. Pugmire, D. Battaglia, and M. A. Langell, "Analysis of the $\mathrm{NiCo}_{2} \mathrm{O}_{4}$ spinel surface with Auger and X-ray photoelectron spectroscopy," Applied Surface Science, 2000, 165(1): 70-84.

[2] F. Iacomi, G. Calin, C. Scarlat, M. Irimia, C. Doroftei, M. Dobromir, et al., "Functional properties of nickel cobalt oxide thin films," Thin Solid Films, 2011, 520(1): 651-655.

[3] S. K. Chang, Z. Zainal, K. B. Tan, and N. A. Yusof, "Surface morphology and crystallinity of metal oxides in nickel-cobalt binary system," Sains Malaysiana, 2012, 41(4): 465-470.

[4] O. A. Hamadi, "Characteristics of CdO-Si heterostructure produced by plasma-induced bonding technique," Proceedings of the Institution of Mechanical Engineers Part L: Journal of Materials Design \& Applications, 2008, 222(1): 65-71.

[5] O. A. Hamadi, "Effect of annealing on the electrical characteristics of $\mathrm{CdO}-\mathrm{Si}$ heterostructure produced by plasma-induced bonding technique," Iraqi Journal of Applied Physics, 2008, 4(3): 34-37.

[6] R. Ding, L. Qai, and H. Y. Wang, "Scalable electrodeposition of cost-effective microsized $\mathrm{NiCo}_{2} \mathrm{O}_{4}$ electrode materials for practical applications in electrochemical capacitors," ECS Electrochem Letters, 2012, 1(3): A43-A46.

[7] M. Hussain, Z. H. Ibupoto, M. A. Abbasi, X. J. Liu, O. Nur, and M. Willander, "Synthesis of three dimensional nickel cobalt oxide nanoneedles on nickel foam, their characterization and glucose sensing application," Sensors, 2014, 14(3): 5415-5425.

[8] M. Y. Ho, P. S. Khiew, D. Isa, T. K. Tan, W. S. Chiu, and C. H. Chia, "A review of metal oxide composite electrode materials for electrochemical capacitors," Nano, 2014, 9(6): 1430002-1-1430002-25.

[9] O. A. Hammadi, "Photovoltaic properties of thermally-grown selenium-doped silicon photodiodes for infrared detection applications," Photonic Sensors, 2015, 5(2): 152-158.

[10] O. A. Hammadi and N. E. Naji, "Electrical and spectral characterization of $\mathrm{CdS} / \mathrm{Si}$ heterojunction prepared by plasma-induced bonding," Optical and 
Quantum Electronics, 2016, 48(8): 1-7.

[11] S. U. Offiah, A. C. Nwanya, S. C. Ezugwu, B. T. Sone, R. U. Osuji, M. Maaza, et al., "Chemical bath synthesis and physico-chemical characterizations of $\mathrm{NiO}-\mathrm{CoO}$ composite thin films for supercapacitor applications," International Journal of Electrochemical Science, 2014, 9(10): 5837-5848.

[12] W. W. Liu, C. Lu, K. Liang, and B. Tay, "A three dimensional vertically aligned multiwall carbon nanotube $/ \mathrm{NiCo}_{2} \mathrm{O}_{4}$ core/shell structure for novel high-performance supercapacitors," Journal of Materials Chemistry A, 2014, 2(14): 5100-5107.

[13] N. A. Bakr, S. A. Salman, and A. M. Shano, " Effect of Co doping on structural and optical properties of $\mathrm{NiO}$ thin films prepared by chemical spray pyrolysis method," International Letters of Chemistry, Physics and Astronomy, 2015, 2: 15-30.

[14] O. A. Hammadi, "Characterization of $\mathrm{SiC} / \mathrm{Si}$ heterojunction fabricated by plasma-induced growth of nanostructured silicon carbide layer on silicon surface," Iraqi Journal of Applied Physics, 2016, 12(2): 9-13.

[15] N. S. Umeokwonna, A. J. Ekpunobi, and P. I. Ekwo, "Effect of cobalt doping on the optical properties of nickel cobalt oxide nanofilms deposited by electrodeposition method," International Journal of Technical Research and Applications, 2015, 3(4): 347-351.

[16] S. Sahoo, S. Ratha, and C. S. Rout, "Spinel $\mathrm{NiCo}_{2} \mathrm{O}_{4}$ nanorods for supercapacitor applications," American Journal of Engineering \& Applied Sciences, 2015, 8(3): 371-379.

[17] O. A. Hammadi, "Characteristics of heat-annealed silicon homojunction infrared photodetector fabricated by plasma-assisted technique," Photonic
Sensors, 2016, 6(4): 345-350.

[18] O. A. Hammadi, M. K. Khalaf, F. J. Kadhim, and B. T. Chiad, "Operation characteristics of a closed-field unbalanced dual-magnetrons plasma sputtering system," Bulgarian Journal of Physics, 2014, 41(1): 24-33.

[19] O. A. Hammadi, M. K. Khalaf, and F. J. Kadhim, "Silicon nitride nanostructures prepared by reactive sputtering using closed-field unbalanced dual magnetrons," Proceedings of the Institution of Mechanical Engineers Part L: Journal of Materials Design \& Applications, 2017, 231(5): 479-487.

[20] O. A. Hammadi, M. K. Khalaf, and F. J. Kadhim, "Fabrication of UV photodetector from nickel oxide nanoparticles deposited on silicon substrate by closed-field unbalanced dual magnetron sputtering techniques," Optical \& Quantum Electronics, 2015, 47(2): 1-9.

[21] O. A. Hammadi, M. K. Khalaf, and F. J. Kadhim, "Fabrication and characterization of UV photodetectors based on silicon nitride nanostructures prepared by magnetron sputtering," Proceedings of the Institution of Mechanical Engineers Part N: Journal of Nanoengineering \& Nanosystems, 2015, 230(1): 32-36.

[22] A. A. Anber and F. J. Kadhim, "Preparation of nanostructured $\mathrm{Si}_{x} \mathrm{~N}_{1-x}$ thin films by $\mathrm{DC}$ reactive magnetron sputtering for tribology applications," Silicon, 2017, pp. 1-4.

[23] M. A. Hameed and Z. M. Jabbar, "Preparation and characterization of silicon dioxide nanostructures by DC reactive closed-field unbalanced magnetron sputtering," Iraqi Journal of Applied Physics, 2016, 12(4): 13-18. 